\title{
Impact of sleeping habits, physical activity and sleeping hours on Insomnia among patients visiting tertiary care hospitals, Lahore
}

Tabeen Irfan $^{1}$, Maham Ulfat ${ }^{1}$, Shahid Bashir ${ }^{1}$, Sidra Khalid ${ }^{1 *}$, Fariha Mehdi $^{1}$, Milhan Tanveer ${ }^{1}$, Fiza Laif ${ }^{1}$, Kinza Seher ${ }^{1}$, Zainab Rashid ${ }^{1}$, Maham Riaz ${ }^{1}$ and Aurang Zeb ${ }^{1}$

1 Institute of Diet and Nutritional Sciences, Faculty of Allied Health Sciences, The University of Lahore-Pakistan

*Corresponding author's email: sidrakhalid.uaf@gmail.com

Citation

Tabeen Irfan, Maham Ulfat, Shahid Bashir, Sidra Khalid, Fariha Mehdi, Milhan Tanveer, Fiza Laif, Kinza Seher, Zainab Rashid, Maham Riaz and Aurang Zeb. Impact of sleeping habits, physical activity and sleeping hours on Insomnia among patients visiting tertiary care hospitals, Lahore. Pure and Applied Biology. Vol. 10, Issue 3, pp819825. http://dx.doi.org/10.19045/bspab.2021.100084

\begin{tabular}{llll}
\hline Received: 01/09/2020 & Revised: 20/11/2020 & Accepted: 26/11/2020 & Online First: 14/12/2020 \\
\hline
\end{tabular}

\section{Abstract}

Insomnia is a condition that affects an individual by inability to get sufficient quality sleep or problem in maintaining sleep that is important for healthy functioning, performance and wellbeing. The sleep quality of an individual is affected by sleeping hours, sleeping habits and amount of physical activity. A cross sectional study based on sample size of 1000 participants, was conducted at Sir Ganga Ram Hospital, Lahore and The University of Lahore Teaching Hospital, Lahore, to find out impact of sleeping habits, sleeping hours and physical activity among patients of insomnia. $48.2 \%$ patients were watching Television before bed. $12.5 \%$ were having snacks at bedtime. $8.9 \%$ patients were eating if they woke up and $35 \%$ patients were waking up to go the bathroom during night. $10.9 \%$ were reading before sleeping. $23.6 \%$ were thinking more before sleeping. $19.1 \%$ were waking up early, could not sleep again and were still tired. $6.7 \%$ patients were facing recurring nightmares. 5.6 percent patients were getting sleep for 1-3 hours, 42.6 percent patients were getting sleep for 4-6 hours, and 51.7 percent patients were getting sleep for 7-10 hours. $50.3 \%$ patients were less active, $43.9 \%$ were moderately active while $5.8 \%$ of them were vigorously active. The study concluded that sleeping habits, sleep hours and physical activity had a significant effect on Insomnia. Patients with poor sleeping habits and sleep duration and who were physically less active reported more symptoms of Insomnia.

Keywords: Circadian rhythm; Depression; Electronic gadgets; Insomnia; Nocturnal polyuria; Physical activity; Restless legs syndrome; Sleeping hours; Sleeping habits; Tertiary care hospitals

Introduction

Insomnia is generally explained by complaints with sleep duration or quality and problems in falling asleep or sustaining sleep, along with considerable discomfort and poor performance at day time [1]. It is a common complaint in clinical practice that can exist on its own or with any other disease. 
In both cases, it requires its own treatment [2]. It is more prevalent in females and old age people. About 25 percent adults are not satisfied with their sleep, 10-15 percent have symptoms of insomnia related with poor functioning at day time, and 6-10 percent adults have insomnia that meets the standards of diagnosis. Insomniac patients usually have weakness, poor mental and physical functioning and disturbed moods [3]. They may experience increased responsiveness in central and peripheral nervous systems [4]. In initial stages, mental health problems (such as anxiety and depression) and physical problems (such as breathing difficulties, pain) are the main causes of sleep issues [5]. Many analyses indicate insomnia as an important risk factor for cardiovascular diseases. It is also a risk factor for high blood pressure in arteries and type 2 diabetes. Neurological disorders are commonly present with insomnia, and insomnia may lead to mental deterioration [6]. There are many factors such as lifestyle habits that lead up to Insomnia. One of them is watching television at bed time. Watching television for $>120 \mathrm{~min} /$ day is independently related with poor quality of sleep [7]. Prevalence of insomnia has increased and sleep duration has reduced due to frequent usage of internet, mobile phones and social media [8]. Alertness, circadian rhythm and sleep are affected by use of electronic gadgets before bed time [9]. Nocturia is a major contributor in causing insomnia. It is a frequent problem in old aged people [10]. Studies suggest that short sleep duration might lead to increased weight due to responses of leptin and ghrelin. This in return reduces energy consumption and increases appetite and energy intake [11]. Nightmares are related to poor sleep quality as they are frightening mental experiences that result in sudden awakenings [12]. Some strategies to prevent insomnia include balanced diet, avoiding stimulants like caffeine, minimizing intake of alcohol, a healthy lifestyle, and daily exercise. Daily physical activity is effective and an easy way to prevent insomnia [13]. Short sleep period and insomnia can be affective on both physical and cognitive health of an individual. Moreover, only avoiding stress, or short-term use of hypnotics are generally not very helpful in treating insomnia. Cognitive behavior therapy is a useful strategy with effects lasting for a long time. It aims to correct maladaptive behavior and thoughts that may have evolved during insomnia or have added to its progression [14].

De Souza SC et al., in 2017 conducted the study to find the association between sleeping quality and time spent watching televisions among teachers from public schools in Londrina, Brazil. Among 959 teachers of age 42 years, teachers going through poor sleep quality were watching television more than $120 \mathrm{~min} /$ day as compared to the teachers watching television less than $60 \mathrm{~min} /$ day, that must be examined in the prevention and medication of sleep interruptions in working population [7]. Tyagi S et al., in 2017, analyzed information from formerly concluded studies of urge urinary excretion. Among 284 women 55\% of them had a greater nocturnal excretion at night and recorded a shorter time of constant sleep before first awaking to void and more terrible rest quality in spite of investing comparative energy in bed [10]. Hysing $\mathrm{M}$ et $a l$., in 2015 conducted a study to investigate relation of sleep with use of screens in daytime and before sleep time. The conclusion showed a direct relationship between sleep and usage of technology which suggests healthy media use should limit the time on electronic devices [15]. In 2013, Anand $\mathrm{S}$ et al., information from the Comprehensive Dialysis Study was used to check the association of physical activity with symptoms of insomnia, restless legs syndrome (RLS), and depression in patients 
new to dialysis. RLS and depression was seen in $29 \%$ and $28 \%$ of patients. Patients new to dialysis normally reported sleep and mood issues. The patients who were less physically active reported symptoms of insomnia, RLS and depression [16]. Inoue $\mathrm{S}$ et al., conducted a study in 2013 to evaluate the association between insomnia and physical activity in a population-based study. Incidence of insomnia can be reduced by regular physical activity, particularly difficulty sleeping sound. Physical activity for 5 days in a week with sufficient movement can improve sleep quality for elder people [13]. Kabrita CS et al., directed an examination in 2014 to recognize the poor sleep quality indicators among Lebanese college students: relationship between night schedule, way of life practices, and sleep habits. study concluded that the incidence of poor rest quality among Lebanese college students is related with less sleep span and night time shifts in weekdays or weekends, particularly the students of evening time [17]. Chen Y et al., in 2018 conducted a study to view Characteristics and relates of duration of sleep, daytime nap, snoring and a sleeping disorder among 0.5 million Chinese people including five lac twelve thousand eight hundred and ninety-one adults of age 30 to 79 years from 10 (5 urban and 5 rural) various regions in China. Among Chinese adults, sleep patterns fluctuate enormously by financial status, way of life and health related variables. The sleeping disorder was related with both poor mental and physical health [8].

The study was designed to identify the link of insomnia with sleeping patterns, physical activity and sleeping hours among patients visiting tertiary care hospitals, Lahore in order to identify the lifestyle factors that can be a risk factor for Insomnia. Once the factors are identified, interventions can be made such as to spread awareness among the individuals and to give solution to the problems related to sleep. This will help to reduce the prevalence of Insomnia in the population.

\section{Materials and Methods}

1000 patients of comorbidities with insomnia were selected from Sir Ganga Ram Hospital, Lahore and The University of Lahore Teaching Hospital, Lahore. Non-probability convenient sampling technique was used to enroll the patients in the study. Patients of both genders, aged above 12 years suffering from insomnia were included. Cross sectional study design was followed to collect data for 4 months (April - July, 2019). Data were analyzed through SPSS version 21.0 and MS Excel (2013). Study was conducted after taking Ethical Approval from the Institutional Review Board (IRB) of The University of Lahore. Written informed consent was taken from all the participants, after explaining the purpose along with advantages and disadvantages of the study. Athens Insomnia Scale (ASI) and pretested questionnaire was used to collect the data from the participants.

\section{Results}

Table 1 shows the sleeping habits among study participants. Analysis revealed $48.2 \%$ patients were having a habit of watching Television before bed. $12.5 \%$ were taking snacks at bedtime, and $8.9 \%$ patients if they wake up during night. $35 \%$ patients reported to woke up to go the bathroom during night. $31.2 \%$ patients had trouble sleeping. $10.9 \%$ were having a habit of reading before sleeping. $28 \%$ patients often woke up during night. $22.3 \%$ patients were unable to sleep again after waking up. Over-thinking before sleep was reported among $23.6 \%$ participants. Awaking up early, inability to fall asleep again and feeling tired whole day was informed by $19.1 \%$. Only $6.7 \%$ patients faced recurring nightmares. Whereas 5\% informed crawling, creeping and tingling sensations in leg while sleeping, 5.1\% sweating profusely during night and $11.5 \%$ 
were having trouble sleeping while lying on their back.

Figure 1 shows the activity level among the participants. Results showed that $50.3 \%$ of patients were less active, $43.9 \%$ were moderately active while $5.8 \%$ of them were vigorously active.
Figure 2 shows that $5.6 \%$ of patient's total amount of sleep per night lied between 1-3 hours, $42.6 \%$ of patients total amount of sleep per night lied between 4-6 hours, 51.7 $\%$ of patients total amount of sleep per night lied between 7-10 hours and $0.1 \%$ of patients total amount of sleep per night lied between 11-14 hours.

Table 1. Frequency and percentage distribution of sleeping habits

\begin{tabular}{|c|c|c|c|c|c|}
\hline \multirow{2}{*}{ S. \# } & \multirow{2}{*}{ Sleeping habits } & \multicolumn{2}{|c|}{ Yes } & \multicolumn{2}{|c|}{ No } \\
\hline & & Frequency & Percent & Frequency & Percent \\
\hline 1 & Watching TV & 482 & 48.2 & 518 & 51.8 \\
\hline 2 & Eating a snack at bed time & 125 & 12.5 & 875 & 87.5 \\
\hline 3 & Eat if woke up during night & 89 & 8.9 & 911 & 91.1 \\
\hline 4 & Wake up to go to washroom & 350 & 35 & 650 & 65 \\
\hline 5 & Trouble falling sleep & 312 & 31.2 & 688 & 68.8 \\
\hline 6 & Reading in bed to sleep & 109 & 10.9 & 891 & 89.1 \\
\hline 7 & Often wake up during sleep & 280 & 28 & 720 & 72 \\
\hline 8 & Can't return to sleep after waking up & 223 & 22.3 & 777 & 77.7 \\
\hline 9 & Thoughts racing in mind when I try to sleep & 236 & 23.6 & 764 & 76.4 \\
\hline 10 & $\begin{array}{l}\text { Wake-up early in the morning, tired still } \\
\text { can't sleep }\end{array}$ & 191 & 19.1 & 809 & 80.9 \\
\hline 11 & Nightmares & 67 & 6.7 & 933 & 93.3 \\
\hline 12 & $\begin{array}{c}\text { Creeping, Crawling and tingling sensation } \\
\text { in legs }\end{array}$ & 50 & 5 & 950 & 95 \\
\hline 13 & Sweating at Night & 51 & 5.1 & 949 & 94.9 \\
\hline 14 & Can't sleep at back & 115 & 11.5 & 885 & 88.5 \\
\hline
\end{tabular}

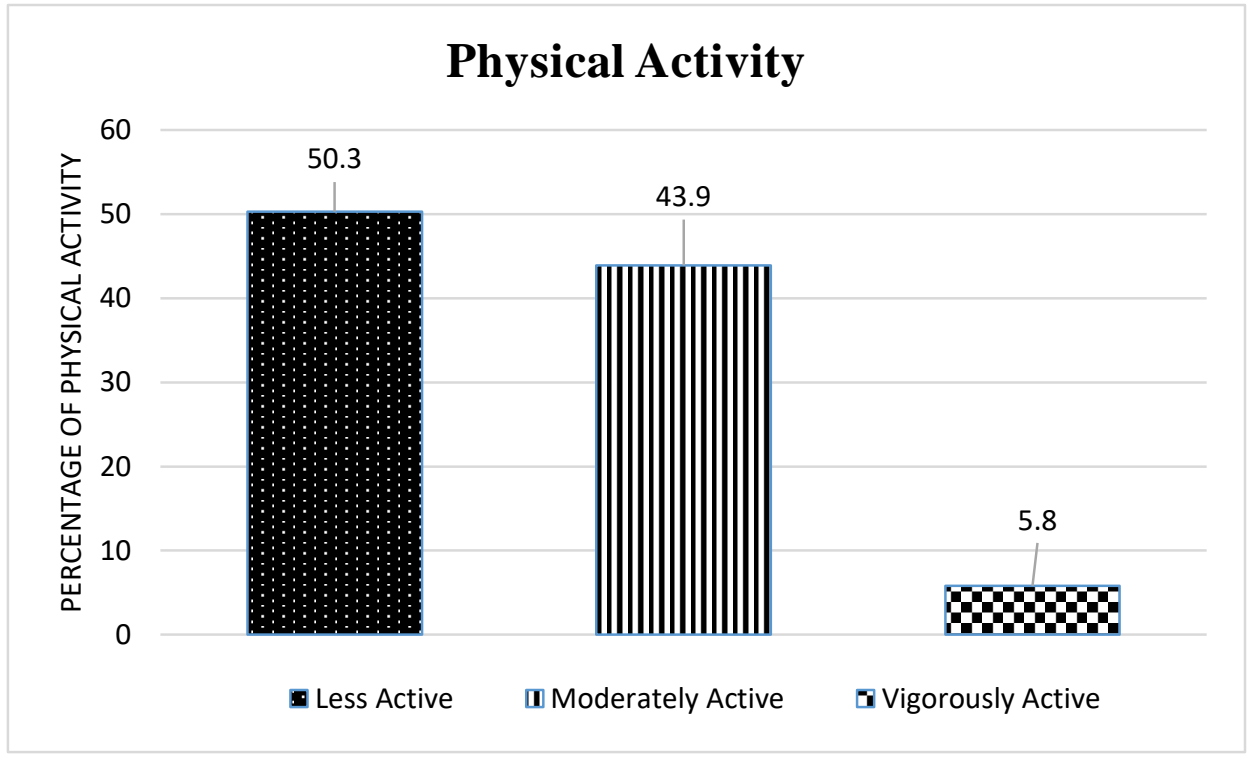


Figure 1. Percentage distribution of physical activity among patients

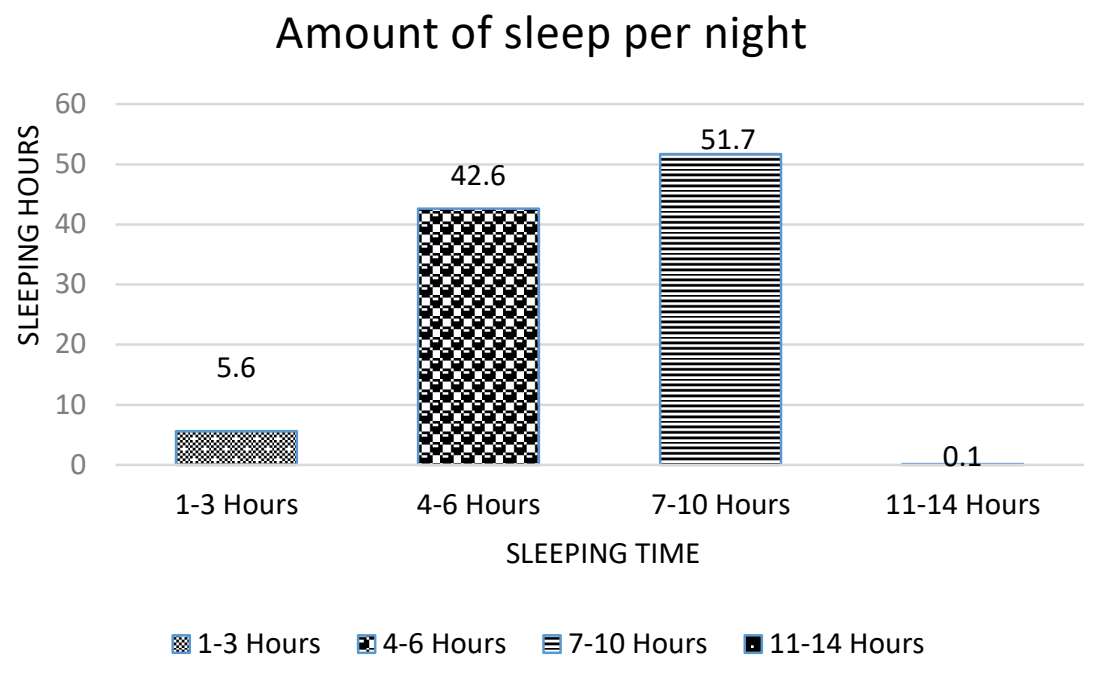

Figure 2. Percentage distribution of patient's total amount of sleep per night

\section{Discussion}

Various sleep habits can be a havoc for the sleep cycle. According to this current study, $48.2 \%$ patients watched Television before bed. Same effect was seen in a study by de Souza $\mathrm{SC}$ and et al in 2017. The results showed that watching television for more than 120 minutes per day was linked with poor sleep quality that should be taken into consideration while preventing and treating sleep disturbances among working population [7]. Gradisar $\mathrm{M}$ et $a l$. , in 2013 conducted a study to analyze the effect of technology use on sleep quality of Americans. Nine out of ten Americans reported using a technological device in the hour before bed like watching TV being the most popular choice. Among a variety of technologies, people using interactive technological gadgets had more sleep problems [18]. The results of this current study showed that $35 \%$ patients woke up to go the bathroom during night. Tyagi $\mathrm{S}$ et al., in 2017, considered guideline information from two formerly concluded studies of urge urinary incontinence. Overall $55 \%$ of the participants were presented with nocturnal polyuria and reported a reduced timing of sleep without any disturbances and poor sleep quality [10]. Zeitzer et al. [19] conducted a research in 2013 to examine the effect of nocturia on objective measures of sleep in older adults with insomnia. More than half of older adults woke up at night due to nocturia. In this latest study, $6.7 \%$ patients faced recurring nightmares. Liu et al. [20] led a study in 2017 to evaluate the association between poor sleep quality, nightmares and non-suicidal self-injury in adolescents. The result was that low sleep quality and periodic nightmares were independently associated with non-suicidal self-injury. In current study, $12.5 \%$ ate snacks at bedtime. $8.9 \%$ patients ate if they woke up during night. Abd Allah E et $a l$., in 2014 concluded that one-third of the studied elderly were suffering from insomnia. Risk factors significantly related with insomnia included depression, smoking, eating just before bedtime, long naps during the day, random sleep hours, and nocturia [21]. Physical activity or exercise can have beneficial effect on sleep quality and quantity. The results of the current study showed that $50.3 \%$ of patients were less active, $43.9 \%$ were moderately active while $5.8 \%$ of them were vigorously active. Similar effects were indicated in a study done by Christin L et al., in 2013 that increased physical activity helps to restore sleep [22]. In 2013, Anand et al. [16] investigated the link between physical activity and insomnia, 
restless legs syndrome (RLS), and depression in patients new to dialysis. $53 \%$ had one out of three symptoms of insomnia that occurred frequently. Patients who were less physically active complained more about symptoms of insomnia, RLS, and depression. Inoue S et al., led a study in 2013 to evaluate the relation between physical activity and insomnia in people of Shizuoka, Japan. Frequent exercise was related to decreased occurrence of insomnia, especially problems in sustaining sleep [13]. The result of the current study showed that $5.6 \%$ of patients total amount of sleep per night lied between 1-3 hours, $42.6 \%$ of patients total amount of sleep per night lied between 4-6 hours, $51.7 \%$ of patients total amount of sleep per night lied between 7-10 hours and $0.1 \%$ of patients total amount of sleep per night lied between 11-14 hours. Kabrita et al. [17] conducted a study in 2014 to find out the predictors of poor sleep quality among Lebanese university students. It was concluded that low sleep quality among Lebanese university students was linked with decreased sleep duration and shifts in sleep timing. Similar findings were seen in a study conducted by Chen Y et al., in 2018 among Chinese adults. Overall, 23\% reported to have less (less than equal to 6 hours) and 16 percent reported to have long (greater than equal to 9 hours) sleep timing, 21 percent having naps at daytime and 22 having constant snoring. Insomnia symptoms were undoubtedly low in those who reported daytime napping and periodic snoring [8].

\section{Conclusion}

Hence concluded poor lifestyle and poor sleeping habits can leads to insomnia.Sleeping habits like watching Television before bed, eating a snack before sleeping, eating in middle of night, waking up to the urge of urinating and no exercise intensifies insomnia. To treat insomnia moderate physical activity should be incorporated in a day as it lowers stress and anxiety which helps sleeping early, watching Television before sleeping and eating snacks at night before sleeping should be avoided so that these habits does not interrupt the sleeping cycle. Overall lifestyles of patients should be modified in order to protect them from Insomnia.

Authors' contributions

Conceived and designed the experiments: $\mathrm{S}$ Bashir, A Zeb \& S Khalid, Performed the experiments: T Irfan, M Ulfat, F Mehdi, M Tanveer, F Laif, K Seher, Z Rashid \& M Riaz, Analyzed the data: A Zeb, S Khalid \& M Ulfat, Contributed reagents/ materials/ analysis tools: S Bashir, A Zeb \& S Khalid, Wrote the paper: T Irfan, M Ulfat \& S Khalid.

\section{References}

1. Morin CM, Drake CL, Harvey AG, Krystal AD, Manber R., Riemann D \& Spiegelhalder K (2015). Insomnia disorder. Nature Revi Dis Prim 1(1): 1-18.

2. Morin CM \& Benca R (2012). Chronic insomnia. The Lancet 379(9821): 11291141.

3. Qaseem A, Kansagara D, Forciea MA, Cooke M \& Denberg T D (2016). Management of chronic insomnia disorder in adults: a clinical practice guideline from the American College of Physicians. Ann of Internal Medi 165(2): 125-133.

4. Levenson JC, Kay DB \& Buysse DJ (2015). The pathophysiology of insomnia. Chest 147(4): 1179-1192.

5. Arroll B, Fernando A, Falloon K, Goodyear-Smith F, Samaranayake C \& Warman G (2012). Prevalence of causes of insomnia in primary care: a cross-sectional study. British J of Gen Prac 62(595): e99e103.

6. Riemann D, Baglioni C, Bassetti C, Bjorvatn B, Dolenc Groselj L, Ellis JG, Espie CA, Garcia-Borreguero D, Gjerstad M, Gonçalves M \& Hertenstein E (2017). European guideline for the diagnosis and treatment of insomnia. $J$ of Sleep Res 26(6): 675-700.

7. de Souza SCS, Campanini MZ, de Andrade SM, González AD, de Melo JM \& Mesas AE (2017). Watching television for more than two hours increases the likelihood of reporting poor sleep quality among Brazilian schoolteachers. Physio \& Beha 179: 105-109. 
8. Chen Y, Kartsonaki C, Clarke R, Guo Y, Yu C, Bian Z, Jiang Q, Li S, Chen J, Li L \& Chen Z (2018). Characteristics and correlates of sleep duration, daytime napping, snoring and insomnia symptoms among 0.5 million Chinese men and women. Sleep Med 44: 67-75.

9. Grønli J, Byrkjedal IK, Bjorvatn B, Nødtvedt $\varnothing$, Hamre B \& Pallesen S (2016). Reading from an iPad or from a book in bed: the impact on human sleep. A randomized controlled crossover trial. Sleep Med 21: 86-92.

10. Tyagi S, Perera S, Clarkson BD, Tadic SD \& Resnick NM (2017). Nocturnal polyuria in older women with urge urinary incontinence: role of sleep quality, time in bed and medications used. The $J$ of Urol 197(3): 753-758.

11. Golley RK, Maher CA, Matricciani L \& Olds TS (2013). Sleep duration or bedtime? Exploring the association between sleep timing behaviour, diet and $\mathrm{BMI}$ in children and adolescents. Intern $J$ of Obes 37(4): 546-551

12. Simor P, Horváth K, Gombos F, Takács KP \& Bódizs R (2012). Disturbed dreaming and sleep quality: altered sleep architecture in subjects with frequent nightmares. Europ arch of Psyc and Clin Neurosci 262(8): 687-696.

13. Inoue $S$, Yorifuji $T$, Sugiyama M, Ohta $T$, Ishikawa-Takata K \& Doi H (2013). Does habitual physical activity prevent insomnia. A cross-sectional and longitudinal study of elderly Japanese. $J$ of Aging and Phys Acti 21(2): 119-139.

14. Cunnington D, Junge MF \& Fernando AT (2013). Insomnia: prevalence, consequences and effective treatment. Medical J of Aust 199: S36S40.

15. Hysing $M$, Pallesen S, Stormark KM, Jakobsen R, Lundervold AJ \& Sivertsen B (2015). Sleep and use of electronic devices in adolescence: results from a large population-based study. BMJ Open 5(1): e006748.

16. Anand S, Johansen KL, Grimes B, Kaysen GA, Dalrymple LS, Kutner NG \& Chertow GM (2013). Physical activity and self-reported symptoms of insomnia, restless legs syndrome, and depression: The comprehensive dialysis study. Hemodialysis Inter 17(1): 50-58

17. Kabrita CS, Hajjar-Muça TA \& Duffy JF (2014). Predictors of poor sleep quality among Lebanese university students: association between evening typology, lifestyle behaviors, and sleep habits. Nature and Sci of Sleep 6: 11.

18. Gradisar M, Wolfson AR, Harvey AG, Hale L, Rosenberg $\mathrm{R}$ \& Czeisler CA (2013). The sleep and technology use of Americans: findings from the National Sleep Foundation's 2011 Sleep in America poll. J of Clin Sleep Med 9(12): 12911299.

19. Zeitzer JM, Bliwise DL, Hernandez B, Friedman L \& Yesavage JA (2013). Nocturia compounds nocturnal wakefulness in older individuals with insomnia. Journal of Clin Sleep Medi 9(3): 259-262.

20. Liu X, Chen H, Bo QG, Fan F \& Jia CX (2017). Poor sleep quality and nightmares are associated with non-suicidal selfinjury in adolescents. Europ Child \& Adol Psy 26(3): 271-279.

21. Abd Allah ES, Abdel-Aziz HR \& ElSeoud ARA (2014). Insomnia: Prevalence, risk factors, and its effect on quality of life among elderly in Zagazig City, Egypt. $J$ of Nurs Edu and Prac 4(8): 52.

22. Lang C, Brand S, Feldmeth AK, HolsboerTrachsler E, Pühse U \& Gerber M (2013). Increased self-reported and objectively assessed physical activity predict sleep quality among adolescents. Phys \& Beha 120: 46-53. 